\title{
Microscopía electrónica de transmisión para observar átomos: principios y desarrollo*
}

\section{Transmission electron microscopy to look at atoms: principles and development}

\author{
Héctor A. Calderón**
}

\begin{abstract}
Electron microscopy is an important tool in characterizing nanomaterials. In its high resolution mode, it is possible to obtain images of the columns of atoms that make up a sample or if the thickness is a monolayer, images of atoms can be obtained. Normally the product image has specific intensities that require proper interpretation, additionally there is a need to consider the electron beam interaction with the sample. In this work, some important characteristics of high resolution and atomic resolution electron microscopy are described. Examples are given with observations in different materials. The beam-sample interaction is given special attention in order to avoid sample damage by an intense electron beam.
\end{abstract}

KEYWORDS: electron microscopy, atomic resolution, spatial resolution, simple-beam interaction, electron dose.

RESUMEN: La microscopía electrónica es una herramienta importante en la caracterización de nanomateriales. En su modalidad de alta resolución, es posible obtener imágenes de las columnas de átomos que conforman una muestra, o si el espesor es una monocapa, pueden obtenerse imágenes de átomos. Normalmente, el producto es una imagen con intensidades específicas, que para ser interpretado correctamente, se debe considerar la interacción del haz electrónico con la muestra. En este trabajo, se describen algunas características importantes de la microscopía electrónica de alta resolución y de resolución atómica. Asimismo, se proporcionan ejemplos de observaciones en materiales específicos. Se da atención especial a la interacción de los electrones con la muestra para obtener imágenes que reproduzcan la distribución atómica genuina y sin modificación por un haz electrónico demasiado intenso.

PALABRAS CLAVE: microscopía electrónica, resolución atómica, resolución espacial, interacción del haz, dosis electrónica.

\section{Introducción}

En el ámbito del día a día se considera que la microscopía en general es un tema que no requiere mayor esfuerzo. Se trata de tomar fotografías y eso es fácil.

Recibido: 3 de abril de 2020.

Aceptado: 19 de mayo de 2020.

* Reconocimiento: El trabajo de microscopía se realizó en la Molecular Foundry del Laboratorio Nacional de Berkeley (LBNL), en instalaciones del National Center for Electron Microscopy (NCEM). El trabajo en el Molecular Foundry fue financiado por el Office of Science, Office of Basic Energy Sciences, del U.S. Department of Energy under Contract No. DE-AC02$05 \mathrm{CH} 11231$.

** Instituto Politécnico Nacional, Escuela Superior de Física y Matemáticas, UPALM Zacatenco. CDMX, 07883. México.

Correo electrónico: calderonbenavidesh@gmail.com 
Este enfoque se comparte en películas o series de televisión y se encuentra en el sentido común de muchas personas. Cualquiera puede tomar fotografías. En realidad, la microscopía tiene relación con imágenes y cuando se trata de luz visible quizás en algún tipo de simplificación, esto pueda "reducirse" a tomar fotografías. Sin embargo, no hay por qué simplificar el arte de tomar fotografías en donde la luz y sus efectos nunca pueden considerarse simples. Por otro lado, la microscopía electrónica sufre de una sobre simplificación similar, incluso cuando las imágenes que se obtienen no pueden considerarse fotografías. En especial, la microscopía electrónica de transmisión (TEM) o de transmisión barrido (STEM) forma imágenes que resultan de la interacción de los electrones como radiación con el objeto o muestra. En algunos casos, las imágenes son fruto de fenómenos de interferencia o de dispersión incoherente. Además, el objetivo principal de la microscopía ha sido durante mucho tiempo determinar las posiciones atómicas en las estructuras que la materia puede tener y para ciertos objetivos relacionarlas con las propiedades de los materiales. El concepto de resolución espacial o mínima distancia que puede distinguirse en una imagen representó durante mucho tiempo las características de los microscopios electrónicos. Con el desarrollo de correctores de aberración, la resolución espacial ha evolucionado a resolución atómica, es decir, la capacidad para distinguir el tipo de átomos directamente en las imágenes. La microscopía no es simple y se necesita mucho empeño para dominar la técnica y conocimiento de la interacción entre electrones y objeto para interpretar las imágenes que se producen.

Este artículo trata sobre el desarrollo de la microscopía electrónica de transmisión, sus avances y principalmente sobre la necesidad de conocer el instrumento y el análisis óptimo de las imágenes para satisfacer el objetivo de la técnica. Esto es, resolver la posición y la naturaleza de los átomos que constituyen un objeto a caracterizar. Para iniciar, se describe la física del instrumento, su construcción básica o lentes que lo conforman y las técnicas de análisis, para concluir con varios ejemplos.

\section{Desarrollo de la microscopía}

La microscopía electrónica de transmisión es de importancia especial por su capacidad para resolver la estructura de la materia y determinar su composición química. Sus metas consisten en determinar el arreglo de átomos en una muestra y, al mismo tiempo, determinar la composición química correspondiente. Los parámetros relevantes en esta disciplina son la resolución espacial, la resolución analítica y la sensitividad del método.

La microscopía electrónica da inicio con los estudios de Ernst Ruska quien logra el premio Nobel de Física en 1986, por su trabajo sobre los fundamentos de la óptica de electrones y el diseño del primer microscopio electrónico en 1933, con un instrumento capaz de lograr una amplificación de 400x. El trabajo teórico de Louis de Broglie inicia el desarrollo del microscopio elec- 
trónico, al encontrar que la longitud de onda es inversamente proporcional al momento. En 1926, Hans Busch descubre que los campos magnéticos pueden actuar como lentes al provocar que los electrones converjan a un foco. Max Knoll y Ernst Ruska desarrollan en 1931 una lente electrónica a partir de embobinados electromagnéticos que puede usarse para obtener una imagen de un objeto irradiado con electrones. Al acoplar dos lentes de electrones se produjo un microscopio electrónico primitivo en 1933, que claramente superó a los microscopios que usan radiaciones en el espectro visible, es decir, microscopios ópticos (The Nobel Prize in Physics 1986). Las ventajas de usar electrones para generar imágenes se fundamentan en la gran resolución espacial que puede obtenerse. La resolución espacial es la distancia más pequeña que puede distinguirse en una imagen y es directamente proporcional a la longitud de onda de la radiación en uso. La figura 1 muestra el concepto de resolución e ilustra el Criterio de Rayleigh que define a la resolución.

La mínima distancia de separación d resuelta por un microscopio está dada por $d=\lambda / \mu \operatorname{sen} \theta \lambda$, en donde $\lambda$ es la longitud de onda utilizada, $\mu \operatorname{sen} \theta$ resume las características del medio ( $\mu$ es el índice de refracción) y la dispersión que se asume a través de una rendija circular. La resolución y d son inversamente proporcionales, por lo cual, este criterio sugiere que para mejorar la resolución es necesario disminuir la longitud de onda y emplear medios con altos índices de refracción. En un microscopio óptico que utiliza luz visible, la resolución es cercana a $400 \mathrm{~nm}$. Por otro lado, la longitud de onda de electrones con una energía de $100 \mathrm{keV}$ es de aproximadamente $0.0037 \mathrm{~nm}$. Estas características podrían fijar un poder de resolución ilimitado, pero es necesario considerar la mecánica cuántica que establece las características de los electrones como ondas y, por lo tanto, introduce una incertidumbre en la determinación de la posición. Lo anterior se convierte en un límite teórico a la resolución para los potenciales de aceleración que normalmente se usan (100 keV a $300 \mathrm{keV})$ del orden de 0.05 a $0.1 \mathrm{~nm}$. Este límite no fue fácilmente alcanzable debido a otro aspecto técnico de impor-

Figura 1. Resolución espacial o mínima distancia distinguible en una imagen. a) Máximos de intensidad resueltos; b) Criterio de Rayleigh de resolución; c) máximos de intensidad no resueltos.

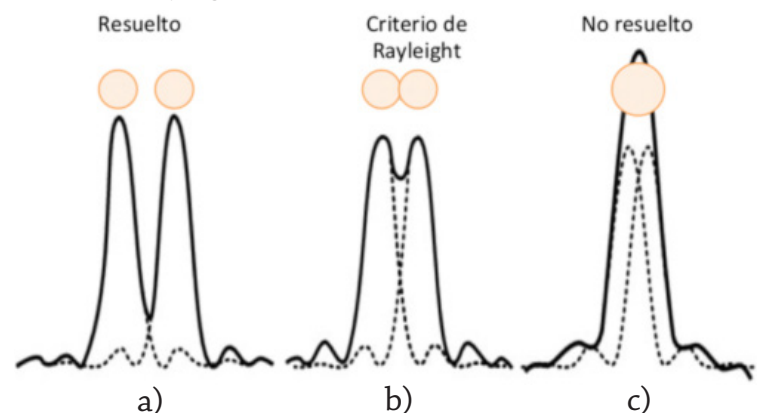

Fuente: Elaboración del autor. 
tancia. La resolución espacial se ve limitada por la presencia de aberraciones en las lentes electromagnéticas. Hasta aproximadamente 2002, la resolución real de los microscopios electrónicos solo alcanzó niveles cercanos a $0.2 \mathrm{~nm}$.

Las aberraciones de las lentes electromagnéticas limitan severamente la resolución de los microscopios electrónicos. Las aberraciones más importantes son el astigmatismo, la aberración esférica, la aberración cromática y el coma. Estas aberraciones han podido corregirse con aditamentos y dispositivos especiales para alcanzar actualmente una resolución espacial de aproximadamente $0.1 \mathrm{~nm}$, un valor muy cercano al límite de resolución teórico. La aberración se presenta en todas las lentes del microscopio electrónico y actualmente se conocen dispositivos de corrección para dos tipos de aberración, la cromática y la esférica, así como dispositivos monocromadores que permiten obtener imágenes con un rango limitado de longitudes de onda. La aberración esférica es uno de los factores limitantes más importantes para la resolución espacial de un microscopio electrónico de transmisión. En este caso, la radiación electrónica que impacta los extremos de la lente es enfocada en un punto diferente a aquella que cruza la lente cerca del eje óptico. Ópticamente la dispersión del enfoque produce imágenes con menor resolución o borrosas. La figura 2 ilustra este efecto, un punto en el objeto (ilustrado con $\mathrm{P}$ ) se convierte en un disco de confusión en $\mathrm{M}$ debido a la diferencia de enfoque de los haces. El Telescopio Espacial Hubble también tuvo este problema y fue necesario corregirlo a través de un dispositivo corrector de aberración esférica. La figura 3 ilustra las diferencias en resolución sin y con corrección de aberración esférica para este telescopio. Los efectos negativos sobre la nitidez y calidad de la imagen se aprecian claramente.

En cuanto a la aberración cromática, se manifiesta cuando la radiación electrónica tiene diferencias en el potencial de aceleración y puede corregirse también por medio de dispositivos especiales incluyendo correctores y monocromadores.

Figura 2. Diagrama de la aberración esférica que provoca un disco de confusión. $\mathrm{C}_{\mathrm{s}}$ es la constante de aberración particular de una lente, $\alpha$ es el ángulo de convergencia y M se sitúa en el plano de mínima confusión. PG es el plano de imagen gaussiano (rayos paraxiales) y se muestran los frentes de onda con (línea continua) y sin aberración esférica (línea punteada).

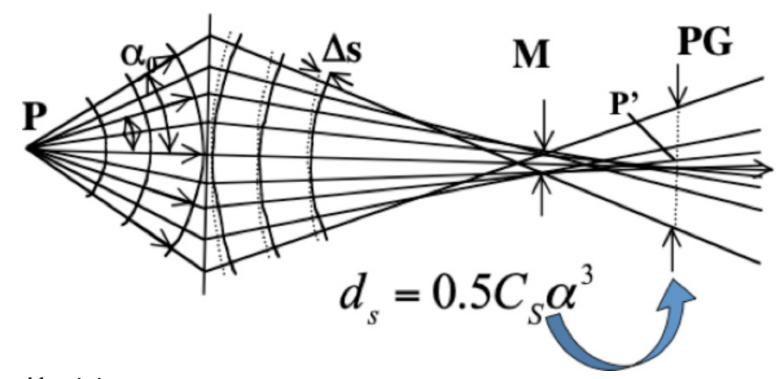

Fuente: Elaboración del autor. 
Figura 3. Imágenes de una cámara de rango amplio en el Telescopio Espacial Hubble. Efecto cualitativo del efecto de la aberración esférica en la calidad de la imagen. NASA Servicing Mission SM1. Shuttle misión: STS-61.

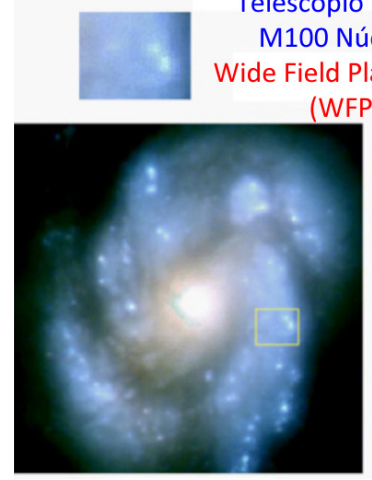

Telescopio Espacial Hubble M100 Núcleo Galáctico FPC2) NASA

Fuente: Elaboración del autor.

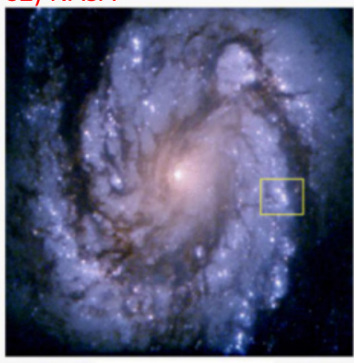

\section{La microscopía electrónica de transmisión}

Los electrones en su carácter de ondas pueden usarse para obtener imágenes en el microscopio electrónico. Existen dos tipos de microscopios electrónicos de alta resolución espacial, el microscopio de transmisión (TEM) y aquel de transmisión barrido (STEM), aunque en algunos casos, se integran ambas modalidades en un solo instrumento. En esencia son similares y pueden relacionarse a partir del llamado principio de reciprocidad que se ilustra en la figura 4. Las figuras 4a-b muestran que las trayectorias de los electrones y los procesos de dispersión elástica, tienen una simetría inversa en función del tiempo; mientras en el TEM, la iluminación paralela produce un punto de interferencia en la imagen (contraste de fase), en el STEM, la iluminación se enfoca en la muestra y se produce un punto en el detector. La figura $4 \mathrm{c}$ incluye un giro de $180^{\circ}$ para hacer más obvio el concepto de simetría inversa. Por supuesto, este argumento en óptica ondulatoria es válido para un haz infinitamente pequeño y las implementaciones técnicas son de importancia debido a que la fuente de electrones no es puntual. De esta manera, cuando se usa un TEM, la iluminación es paralela (figura 4b) y produce una imagen directa desde el primer instante del tiempo, es única y la misma, siempre y cuando el haz no altere la constitución de la muestra. Toda la imagen transmitida en TEM se forma al mismo tiempo y es producto de interferencia coherente entre el haz electrónico y las columnas de átomos en la muestra, asumiendo un material cristalino, esto es, un interferograma coherente, como se indica en la figura 4 b. Un punto en la imagen representa un máximo de intensidad de interferencia y no coincide con las posiciones atómicas del objeto. En este caso, las lentes se usan para amplificar la imagen. La imagen no muestra posiciones exactas de los átomos en la muestra sino máximos de intensidad del interferograma, este interfero- 
grama y su contraste de fase, en cuanto a distancias entre máximos de intensidad, tienen valores muy cercanos a aquellos de la red cristalina, pues se forman picos de intensidad con distancias muy similares a aquellas de la red que dan origen a la interferencia. Sin embargo, sus características y contraste no pueden relacionarse de manera intuitiva con la naturaleza de la muestra. De manera natural es posible lograr una buena resolución espacial, pero las imágenes simples de contraste de fase (TEM) contienen un contraste atómico o relacionado con la constitución de la muestra que puede interpretarse solo cuando se considera la interferencia. En el caso de un STEM, hay varios métodos de operación y normalmente se utiliza el campo oscuro con un detector anular para imágenes con resolución atómica. En este caso, se obtiene un contraste incoherente a altos ángulos de dispersión y que puede relacionarse con la constitución de la muestra, es decir, se tiene contraste $Z$ que depende del número atómico, o sea, de la naturaleza de los átomos en interacción con el haz electrónico. En consecuencia, el haz electrónico debe enfocarse al mínimo tamaño posible y para formar una imagen completa se realiza un barrido en áreas seleccionadas. A menor área barrida, mayor se vuelve la amplificación. La imagen se forma moviendo el haz y procesando la intensidad dispersada en cada posición del haz durante el barrido. Entonces, en general se emplea un haz enfocado para formar imágenes en una secuencia de puntos y se logra barriendo la muestra en un área predeterminada y acorde con la magnificación deseada. La intensidad dispersada a altos ángulos de dispersión en un detector anular depende de las características de la muestra, ver figura 4b. En resumen, la figura 4 ilustra que en TEM de alta resolución (HRTEM) se obtiene un contraste de la fase por interferencia y en el STEM se obtiene un contraste $Z$ (número atómico) basado en intensidades dispersadas pero incoherentes y relacionado con la naturaleza de la muestra. En muchos casos, el TEM y el STEM utilizan correctores de aberración que van situados como se indica en la figura $4 \mathrm{c}$, y como consecuencia del proceso de formación de imágenes arriba descrito. En el TEM, la imagen se forma usando una lente objetiva de manera que la corrección de aberración instrumental se realiza en ese punto para lograr una imagen libre de aberración o corregida. En el STEM, el corrector de aberración se coloca en la lente condensadora de manera que pueda corregirse la aberración del haz que barre la muestra y la imagen resultante esté libre de aberración.

Las características de los electrones y la corrección de aberraciones han hecho posible alcanzar los límites teóricos de la resolución espacial. La figura 5 ilustra el desarrollo tecnológico de la microscopía electrónica como función del tiempo. La fortaleza de los electrones como radiación es clara y supera a otras radiaciones como neutrones o rayos $\mathrm{X}$ por su mayor brillantez, una gran resolución espacial, mayor dispersión elástica (sin pérdida de energía) y por su gran interacción con la materia. Es precisamente en esta última parte en donde la integridad de los materiales nano y microestructurados debe considerarse. No puede asumirse que la explotación de las propiedades mencionadas al usar un haz de electrones y en el borde de la tecnología, mantendrá 
Figura 4. Tipos de microscopios electrónicos con alta resolución, TEM (Transmisión) y STEM (Transmisión/barrido). a) Esquemas de iluminación en STEM y TEM mostrando el principio de reciprocidad. Las trayectorias de los electrones y los procesos de dispersión elástica tienen una simetría inversa en el tiempo. b) Formación de imágenes en TEM (contraste de fase) y STEM (contraste Z). c) Esquemas de iluminación en TEM y STEM incluyendo correctores de aberración.

(a)

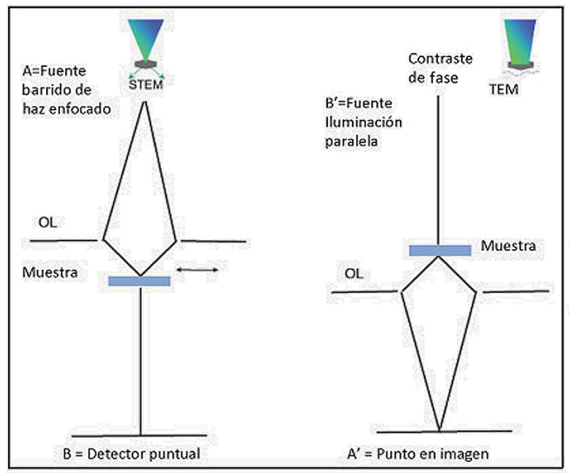

(b)

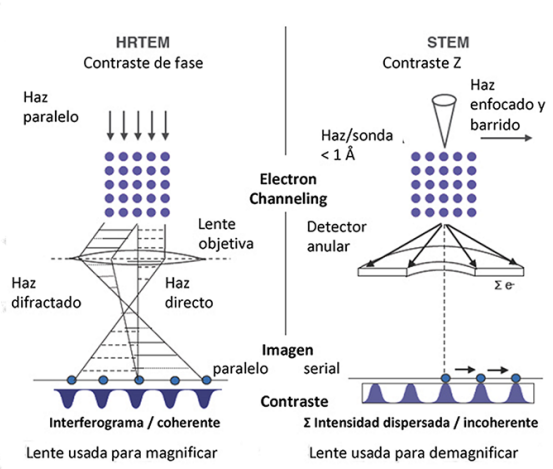

(c)

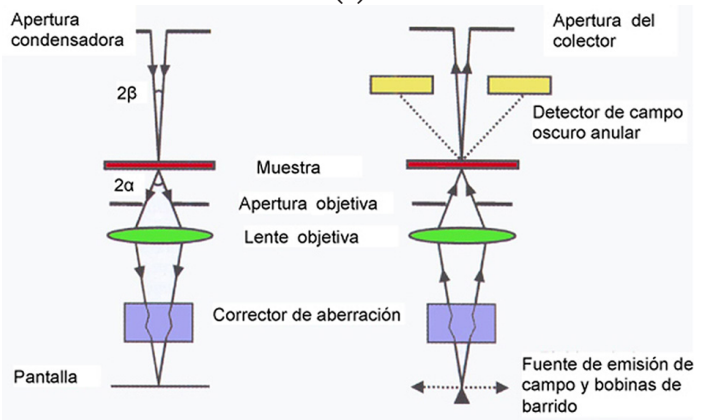

Fuente: Elaboración del autor.

las muestras con la integridad deseada. En consecuencia, el deterioro de las muestras nanoestructuradas es un fenómeno adicional a considerar en el uso de haces electrónicos en TEM o STEM.

La interacción entre el haz de electrones y la muestra puede generar cambios en las estructuras o arreglos atómicos originales de la muestra. Tales cambios pueden suceder por mecanismos como desplazamientos de átomos o difusión en intervalos de tiempo muy cortos y son, en consecuencia, difíciles de detectar. Como se muestra en la literatura (Kisielowski et al., 2001), no hay un límite mínimo para desplazar átomos de superficies o defectos debido a que las energías de enlace pueden variar y ser muy pequeñas en comparación con la energía de los electrones en el haz. En un microscopio electrónico eficiente, se requiere alrededor de 10,000 e-/Å2 en el haz para detectar un átomo de C. En materia suave, la muestra comienza a dañarse si la dosis en el haz excede los $20 \mathrm{e}^{-}$/ Å2 (biología). Por lo que existe un enorme intervalo en la dosis entre lo necesario 
Mundo Nano | ARTículos DE REVISIóN | www.mundonano.unam.mx

13(25), 133-156, julio-diciembre 2020 | https:// doi.org/10.22201/ceiich.24485691e.2020.25.69649

Héctor A. Calderón

Figura 5. Desarrollo de la resolución en equipos de microscopía. El límite físico de 1 Å se alcanzó hace una década.

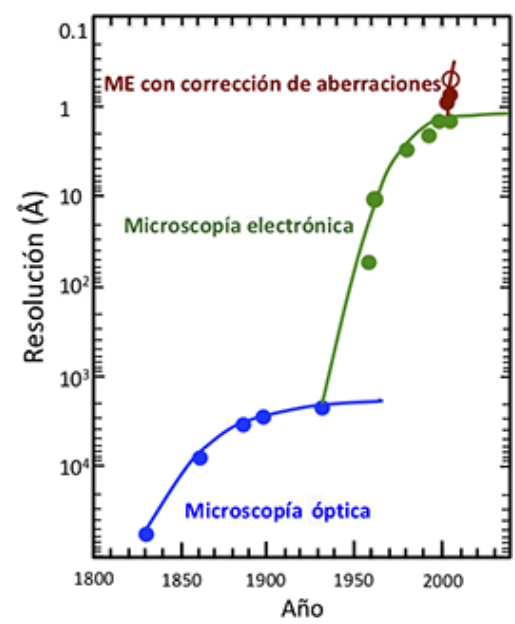

Fuente: Adaptada de Pennycook et al. (2006).

y el límite de daño, con un valor de aproximadamente 500 para carbono y de alrededor de 50 para átomos más pesados. Hay varios métodos para superar este intervalo entre los que se encuentra el uso de bajas dosis, la crio microscopía, el uso de placas de fase, microscopía electrónica de tiempo resuelto, entre otros. La figura 6 cubre algunas de estas posibilidades. En principio es posible producir imágenes con bajas dosis, reduciendo la iluminación y el número de electrones que impacta a la muestra. Otro desarrollo probable se encuentra en manipular el haz en tiempo, por ejemplo, pulsando la corriente y produciendo un haz intermitente con la dosis adecuada. Controlando el número de electrones en sitios de la muestra e intermitentemente en el tiempo hará posible reducir la dosis de observación y obtener imágenes genuinas de las muestras sin daño alguno. Asimismo, controlando la dispersión de electrones con haces reducidos puede hacer posible 'cuantizar' la interacción y obtener imágenes sin distorsión en cualquier muestra. Sin duda, el mejoramiento de cámaras, haciéndolas de mayor dimensión en cuanto al número de pixeles y a su sensitividad permitirá también reducir la interacción con el haz sin mermar la calidad de las imágenes.

\section{Microscopía electrónica para materiales nanoestructurados}

Los materiales nanoestructurados requieren de una caracterización con alta resolución espacial en donde el uso de TEM o STEM en bajas dosis es importante. La investigación de materiales puede convertirse en un diseño apropiado de materiales cuando se conoce la relación entre las propiedades y la estructura, es decir, la posición y distribución de los átomos en el nanomate- 
Figura 6. Resumen de métodos para contrarrestar daño por radiación y correspondientes avances tecnológicos realizados o por realizar en la microscopía electrónica.

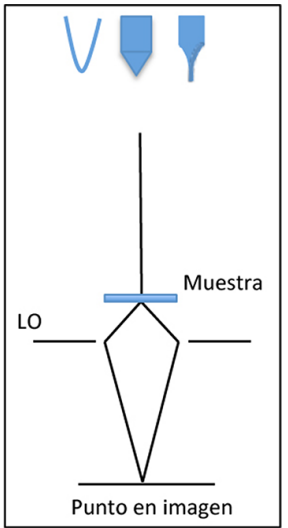

Fuente: Elaboración del autor.

\author{
Cañón de electrones: \\ Control de haces electrónicos en \\ espacio y tiempo: \\ Manipular electrones hacia \\ sitios específicos de la muestra \\ Permitir resolución temporal \\ Dispersión de electrones \\ Microscopía electrónica \\ cuántica \\ Detectores \\ Mejorar cámaras y esquemas \\ de detección
}

rial. En lo que respecta a la posición de los átomos, la figura 7 muestra que un ligero cambio en la distancia interatómica del orden de $0.1 \mathrm{~nm}$ puede alterar el intervalo de energía (gap) en semiconductores en aproximadamente $50 \mathrm{meV}$, lo cual equivale al calor de fusión del hielo. En consecuencia, para el diseño de las propiedades ópticas de los semiconductores (ingeniería del intervalo) o para las propiedades de nanoestructuras en general, es necesario poder medir y controlar las posiciones atómicas con una precisión del orden de picometros. Para lograrlo, la resolución del microscopio tiene que superar

Figura 7. Precisión requerida en la posición de los átomos.

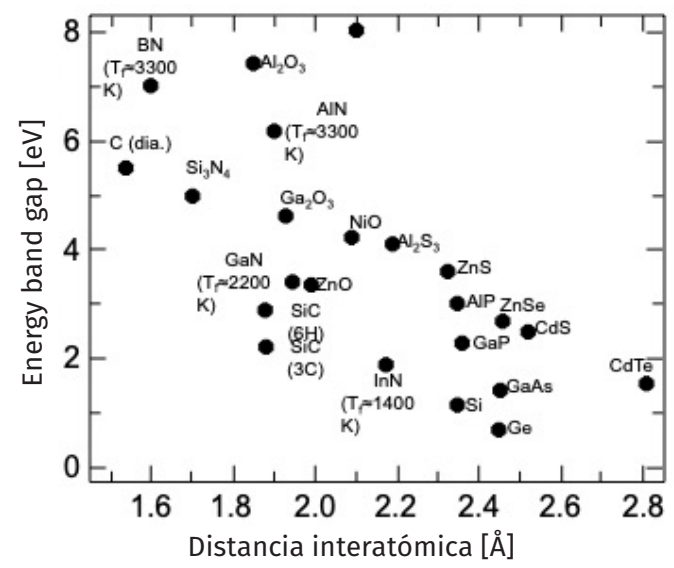

Nota: La banda prohibida en semiconductores varia considerablemente para variaciones del orden de $1 \AA$.

Fuente: Kisielowski et al. (2006). 
$1 \AA$, lo cual, en el caso del Si, permite observar siete diferentes distancias interatómicas o interplanares; así, el análisis puede realizarse con diferentes ejes de zona o de proyección, dando la oportunidad de hacer una caracterización en tres dimensiones y adicionalmente reconocer especies atómicas en las imágenes. Esto es, lograr una resolución atómica (resolviendo especies atómicas y posiciones) en adición a la resolución espacial. En este objetivo, es posible mejorar la resolución espacial con diferentes métodos. En la literatura, la resolución alcanzada con STEM incoherente ha sido de $0.078 \mathrm{~nm}$ (Nellist, 2016) y con el uso de altos voltajes se llega a $0.089 \mathrm{~nm}$ de resolución puntual (Mobus, 1997). Usando TEM y la reconstrucción directa de ondas se alcanza una resolución de $0.085 \mathrm{~nm}$ (Kisielowski et al., 2001) con una compensación de la aberración esférica (Haider et al.,1998).

TEM y STEM son dos métodos posibles para alcanzar la resolución espacial necesaria y para lograr resolución atómica, lo cual conlleva al control de propiedades de los nanomateriales al asegurar la determinación de posiciones atómicas con la precisión suficiente. En estas técnicas se tienen trayectorias de electrones y procesos de dispersión elástica con una simetría inversa en el tiempo. TEM es ideal para capturar señales específicas rápidamente y con un amplio campo de visión, STEM es ideal para extraer la máxima información de un volumen dado al detectar varias señales simultáneamente. La diferencia en su uso se encuentra en el problema específico a resolver. No obstante, si se cuenta con la suficiente resolución espacial y con acceso a resolución atómica, el principal problema en nanomateriales es caracterizar la muestra sin dañarla. El interés se centra, entonces, en controlar la dosis del haz de electrones, es decir, en conocer cuántos electrones impactan la muestra por unidad de tiempo y de área. La dosis con un haz paralelo normalmente se encuentra entre 1 y $10,000 \mathrm{e}^{-} / \AA^{2} \mathrm{~s}$ (TEM) y en el caso de un haz enfocado en valores de 6 a 600 x $10^{6} \mathrm{e}^{-} / \AA^{2} \mathrm{~s}$ (STEM), lo que se traduce en un intervalo de tiempo para adquisición de imágenes de entre 0.1 y $10 \mathrm{~s}$ para un haz amplio y entre $1 \mathrm{~ms}$ y $100 \mathrm{~ms}$ para un haz enfocado. Claramente es muy difícil satisfacer estos criterios y se requiere una estrategia diferente para disminuir la dosis que impacta un nanomaterial y emplear las características específicas de TEM o STEM. Resumiendo, en el caso del TEM el contraste puede formarse por interferencia entre los haces que llegan al detector, esto es, el contraste depende de las diferencias de fase y se le llama contraste de fase, que puede producirse por el espesor de las muestras y por su composición además de las aberraciones. Este alcanza valores óptimos de alrededor del 20\%, lo que hace el método ideal para muestras delgadas que incluyen elementos químicos ligeros. El contraste de fase utiliza dispersión débil y, por lo tanto, normalmente es necesario hacer simulación de imágenes para una interpretación correcta. En el caso del STEM normalmente se usa en modo de campo oscuro anular (con contraste Z) usando dispersión incoherente sobre un detector angular. En esta técnica se integran muchos haces dispersados pero con una baja eficiencia en el uso de electrones. Las intensidades de los haces difrac- 
tados en imágenes en contraste $\mathrm{Z}$ representan apenas un $1 \%$ del haz incidente. En general, STEM resulta ideal para elementos pesados o muestras relativamente más gruesas en comparación con el TEM debido a la naturaleza de la dispersión incoherente. El contraste Z permite utilizar condiciones de operación intuitivas, por ejemplo, para enfocar la imagen.

La interacción entre el haz de electrones y la muestra debe considerarse de manera primordial ya que puede propiciar cambios indeseables en la estructura y arreglo atómico de materiales que deben evitarse durante su caracterización por microscopía electrónica. Todas las condiciones operativas y características de los métodos específicos deben aprovecharse para reducir dicha interacción y mantener sus atractivos en cuanto a resolución atómica y espacial. Estos cambios a la estructura de nanomateriales pueden darse en un instante y pueden no notarse al operar el equipo, por lo cual es necesario usar condiciones específicas y que comprobadamente eviten daño. En la medida de las condiciones descritas, los microscopios electrónicos actuales pueden equiparse con correctores de aberración cromática, esférica y monocromadores en la columna del instrumento. Tales aditamentos crean un equipo costoso y difícil de operar, pero eso no es suficiente para lograr el objetivo final. El objetivo final es lograr una buena resolución espacial y una resolución atómica en nanomateriales pero sin cambios a su distribución atómica. En consecuencia, cualquiera que sea el método elegido de observación, TEM o STEM, la interacción haz electrónico-muestra no debe ignorarse a riesgo de obtener imágenes de una muestra alterada por el haz.

\section{Reconstrucción de ondas de salida en TEM}

Entre los métodos de operación basados en el TEM se encuentra la reconstrucción de ondas de salida. A continuación se describirá la reconstrucción de la onda de salida y su aplicación para obtener imágenes de fase y de amplitud. Es decir, a partir de la ecuación de onda de salida reconstruida y por métodos numéricos en una rutina numérica específica, se logra descomponer la onda en sus componentes para la obtención de imágenes de cambios de fase y de cambios en amplitud de la onda que entra a la muestra. En consecuencia, se obtienen imágenes que caracterizan la muestra. Las imágenes de fase cuentan con contraste atómico y buena resolución espacial. La imagen de fase es importante debido a que conserva la mayor parte de la información de la muestra. La importancia de la imagen de fase puede apreciarse en la figura 8 en donde dos imágenes se emplean para generar una imagen de fase y otra de amplitud. Posteriormente, la imagen de fase de uno de los objetos se mezcla con la imagen de amplitud del otro. En la imagen resultante predominan las características de la imagen de fase. Adicionalmente, el método de reconstrucción de onda de salida permite reducir la deslocalización del objeto que reduce la calidad de la imagen. En algunos casos, la formación de imágenes de interferencia en el TEM pierde algunas frecuencias y se producen imágenes deslocalizadas como se ilustra en la figura 9. 
Mundo Nano | ARTículos DE REVISıón | www.mundonano.unam.mx

13(25), 133-156, julio-diciembre 2020 | https:// doi.org/10.22201/ceiich.24485691e.2020.25.69649

Héctor A. Calderón

Figura 8. Importancia de la imagen de fase.

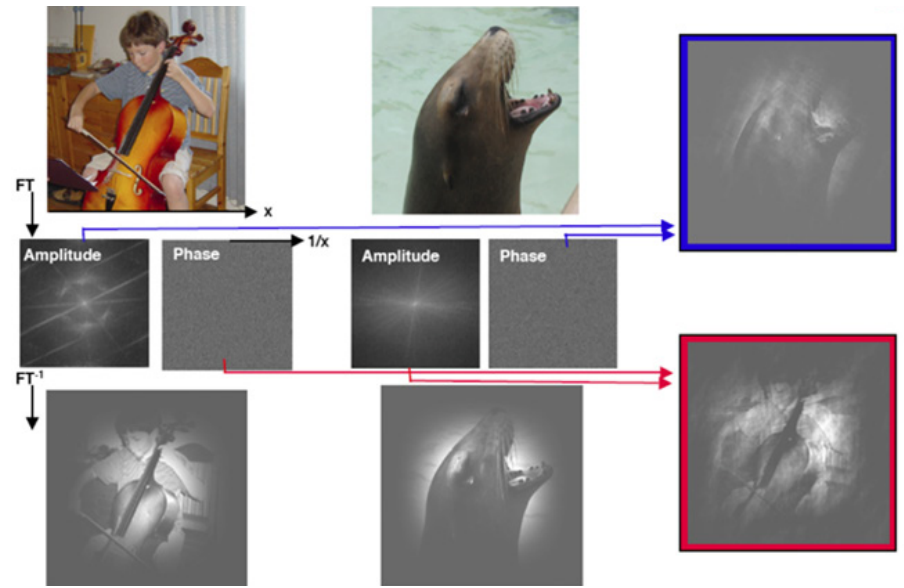

Nota: Se muestran dos imágenes y su correspondiente fase y amplitud. Al combinar la fase de una imagen con la amplitud de la otra, la imagen resultante muestra características de la fase utilizada. Fuente: Elaboración del autor.

La necesidad de hacer una reconstrucción de onda también puede expresarse a través de la función de transferencia de contraste. En esta función se mezclan las fases y las amplitudes, y puede utilizarse para estimar a través del inicio de fluctuaciones, el vector de dispersión $(\boldsymbol{q})$ máximo que puede interpretarse directamente. La imagen que se observa en TEM de alta resolución (HRTEM) normalmente es un interferograma de electrones, la función de transferencia y el inicio de sus oscilaciones en función de $\boldsymbol{q}$ puede ayudar a determinar el rango en que inician las oscilaciones y en donde el contraste puede interpre-

Figura 9. Deslocalización de imágenes.
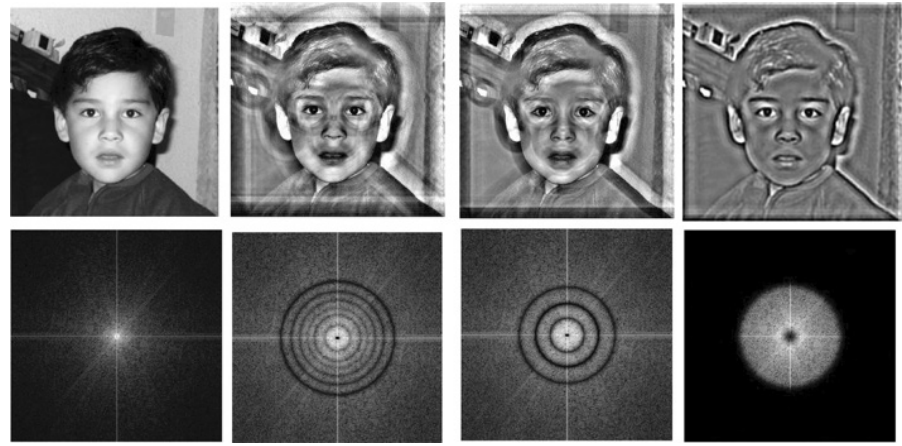

Nota: Se muestra una secuencia de imágenes a las que se les ha sustraído diversas frecuencias y pierden nitidez o se deslocalizan debido a que las posiciones adquieren incertidumbre. La sustracción de frecuencias específicas se realiza en la transformada de Fourier correspondiente. La imagen deslocalizada se obtiene al realizar una transformada inversa a la FFT incompleta.

Fuente: Elaboración del autor. 
tarse directamente. El contraste más alto no siempre es aquel de las posiciones correspondientes a columnas de átomos en la muestra, debido a variaciones de contraste. Estas complicaciones pueden evitarse y subsanarse a través de la reconstrucción de ondas de salida en donde la interpretación de imágenes es directa. La figura 10 muestra la evaluación de la función de transferencia de contraste (FTC) y la consecuente deslocalización de la imagen para dos voltajes de aceleración y asumiendo grafeno como muestra. La imagen de grafeno corresponde al voltaje de aceleración de $80 \mathrm{keV}$. Los patrones en la imagen cambian para una misma configuración atómica en una escala equivalente a la variación inherente de foco $\Delta$ f. Esta variación de foco se considera estrecha $(0.7-1 \mathrm{~nm})$ cuando el ancho o espesor de las muestras normalmente es ligeramente mayor.

Las imágenes mostradas son diferentes entre sí, y aunque pueden reconocerse la estructura y distribución atómica del grafeno (hexágonos), se tiene una fuerte variación de contraste. Los máximos de intensidad no corresponden a las posiciones atómicas sino al resultado de interferencia. En la figura 10 puede verse que para alcanzar una resolución espacial dentro del límite de información (FTC sin cambio de signo) es necesario realizar una reconstrucción de onda. Esta reconstrucción de onda debe hacerse a partir de imágenes experimentales y usando una función de apertura de la lente para lograr reconstruir la imagen de fase proyectada y la estructura atómica correspondiente. En otras palabras, se trata de una reconstrucción holográfica que se realiza de manera cuantitativa con la ayuda de diversas imágenes a diversos enfoques. Este es un problema clásico para resolver el problema de fase u holo-

Figura 10. Función de transferencia de contraste (FTC) en relación con el vector de dispersión q, para dos energías de aceleración del haz electrónico, 300 keV y 80 keV.
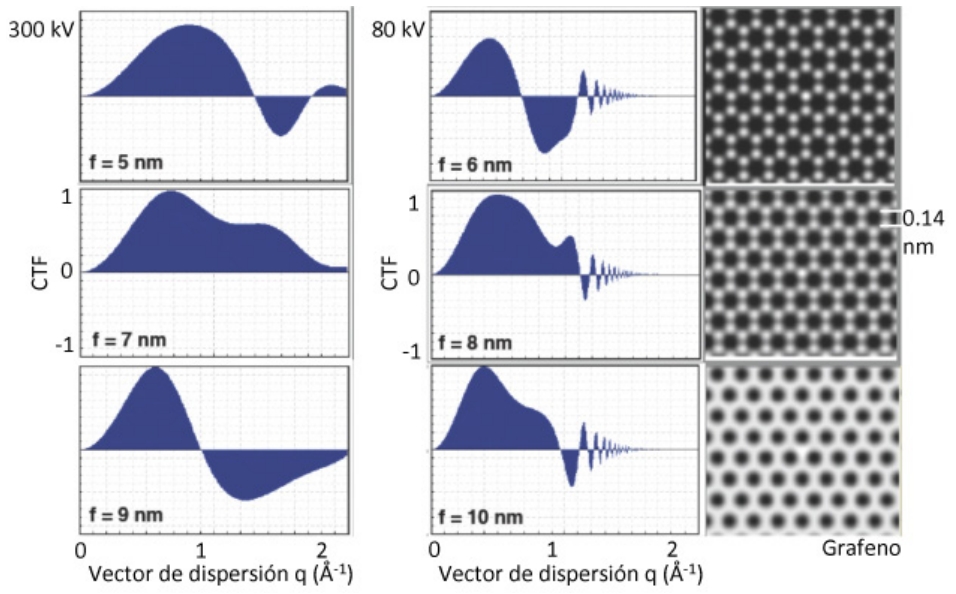

Nota: Se muestra la FTC para tres diferentes posiciones de enfoque indicadas en la figura. Los patrones en las imágenes cambian en una escala relacionada con el ancho de enfoque. El enfoque usado es $f$. Fuente: Elaboración del autor. 
grafía (Lichte y Lehman, 2008) que se esquematiza en la figura 11. Experimentalmente, se usa un número $\mathrm{n}$ de imágenes a diferentes desenfoques para poder calcular la onda de salida (Gerchberg y Saxton, 1972; Hsieh et al., 2004).

La reconstrucción de la onda electrónica de salida es un procedimiento necesario para recuperar una imagen de la muestra con las posiciones atómicas precisas. El método forma parte básicamente de holografía en línea, en donde el objetivo es encontrar la función de onda de salida óptima $\Psi_{0}$ con dos ondas límite en la función $\chi^{2}$ : la onda plana incidente $\Psi_{0}$ y la onda de salida $\Psi_{\mathrm{e}}$. El material experimental necesario consiste en una serie focal de $n$ imágenes $(n>3)$. En esta técnica holográfica se realiza una sobreposición de una onda de referencia y del objeto y es iterativa empleando un método de entropía máxima y el algoritmo de Gerchberg-Saxton, usando una auto correlación. Hay varias ventajas en el uso de estas condiciones (Hsieh et al., 2004) y se encuentra implementado en varios paquetes de software, por ejemplo, MacTempass ${ }^{\circledR}$ (Kilaas, R.). El resultado es una función de onda de salida (EWF) y puede usarse para obtener imágenes de fase y de amplitud que pueden ser interpretadas directamente en cuanto a resolución atómica. La EWF se encuentra idealmente libre de desviaciones y artificios en la imagen y se determina exclusivamente con el objeto y la longitud de onda del electrón $\lambda$. Por el contrario, una imagen en alta resolución de TEM (HREM) es una convolución del objeto y las propiedades del microscopio como resultado de la aberración esférica $C_{\mathrm{s}}$, cromática $C_{\mathrm{r}}$ y el desenfoque $\Delta \mathrm{f}$. El límite de información del microscopio no se ve alterado. En este método, la función de onda se reconstruye a partir de una serie de imágenes to-

Figura 11. Técnicas de holografía para resolver el problema de fase $\left(I=\Psi \Psi^{*}\right)$. a) Óptica; b) óptica electrónica fuera del eje; c) holografía en línea con electrones. Intensidad I, la amplitud de onda en la imagen $\Psi$ y su conjugado $\Psi^{*}$.

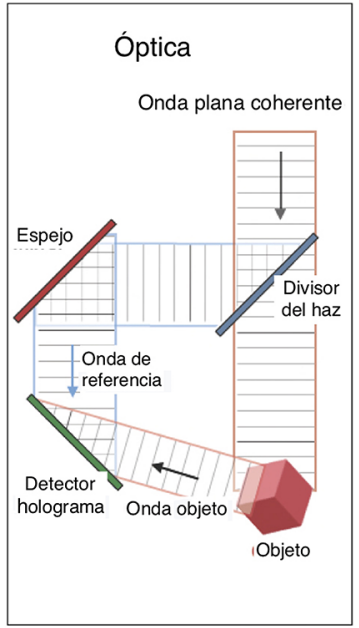

Fuente: Elaboración del autor.
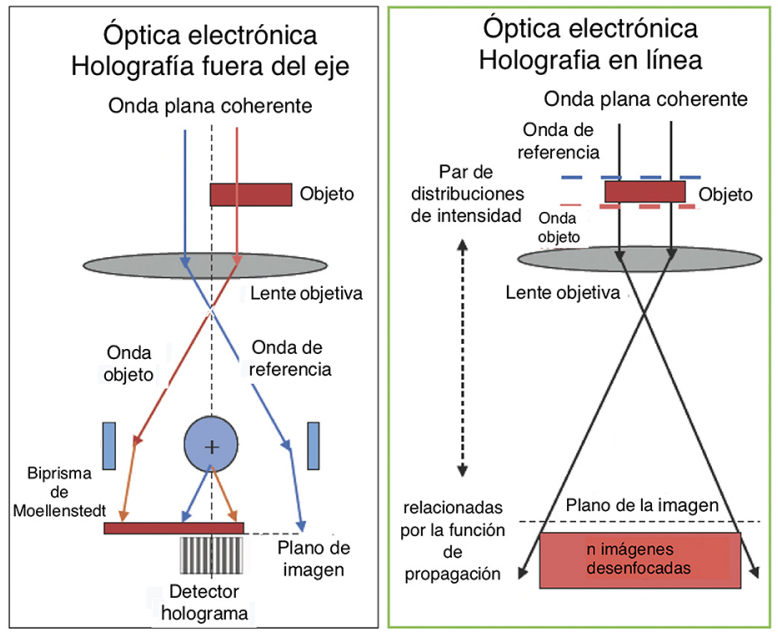

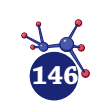


madas en valores de enfoque equidistantes. Es importante enfatizar que la reconstrucción de onda debe realizarse en valores de desenfoque cercanos al desenfoque de Lichte. Este valor es ideal para realizar hologramas (Lichte, 1991). Hay que recordar que la intensidad en TEM es una función de la amplitud dispersada y que no está relacionada con la fase de la onda de salida. Se ofrece a continuación una comprobación simplificada de este problema llamado el problema de fase, y en donde se usa la naturaleza ondulatoria del electrón. La intensidad I en una imagen de TEM de alta resolución puede escribirse como sigue:

$$
I=\Psi \Psi^{*}=A e^{i \phi}=A e^{-i \phi}
$$

en donde $\Psi$ y $\Psi^{*}$ son la amplitud de onda y su conjugado en la imagen, respectivamente, y A representa el módulo o amplitud con $\phi$ como la fase. Por lo tanto, en una imagen de TEM no se recupera la fase y el método de reconstrucción de ondas de salida ofrece, por lo tanto, una posible alternativa útil. En dicho método, es necesario resolver un sistema de ecuaciones y recuperar la fase de la onda de salida, así como la amplitud de la misma. Es en esencia un método holográfico pero en línea y utilizando imágenes diferentes en lo que respecta a su desenfoque pero conservando todos los otros parámetros del instrumento constantes y bajo control. Detalles de esta técnica pueden encontrarse en la referencia (Lichte y Lehman, 2008).

La reconstrucción de onda de salida es el método ideal para recuperar la posición de los átomos en un nanomaterial. El microscopio tiene también que ser caracterizado de manera que todos sus parámetros importantes se calibren y conozcan, entre ellos están los siguientes: constante de aberración esférica $C_{s}$, ancho de desenfoque $\Delta \mathrm{f}$, ángulo de convergencia del haz electrónico, magnificación efectiva, tasa de muestreo o tamaño efectivo del pixel. Aunque para un usuario obtener esta información puede resultar engorroso, es un trabajo necesario y útil para los encargados del equipo que conlleva al conocimiento y calibración del instrumento.

A continuación se ofrecen ejemplos de observaciones en materiales sensibles al haz. En todos estos casos se han usado microscopios con corrección de aberración esférica y con monocromador, de manera que la dispersión de energía alcanza un máximo de 100 meV (Tiemeijer et al., 2012). La iluminación del haz adquiere una forma elipsoidal como la que se esquematiza en la figura 12 y se conoce como iluminación de Nelson. En esta situación, se pueden intercambiar altas y bajas dosis en segundos, moviendo el haz a través de los controles del microscopio. El control de la dosis se puede hacer tanto en dirección horizontal como vertical. Durante la calibración del instrumento a diferentes energías de aceleración es posible seleccionar la opción más conveniente en lo que respecta a contraste optimizado o corrección de aberraciones remanentes. En el caso del microscopio utilizado para los ejemplos siguientes, se encuentra que $80 \mathrm{keV}$ es la opción con mejor contraste y que para voltajes menores, resulta más complicado corregir aberraciones remanentes. El con- 
Mundo Nano | ARTículos DE REVISıón | www.mundonano.unam.mx

13(25), 133-156, julio-diciembre 2020 | https:// doi.org/10.22201/ceiich.24485691e.2020.25.69649

Héctor A. Calderón

Figura 12. Iluminación para un haz electrónico monocromado y enfocado, conocida como Iluminación nelsoniana. Dependiendo de la zona del haz enfocado en uso, es posible obtener imágenes con altas o bajas dosis. En el esquema, la apertura se sitúa en la región de la lente condensadora del microscopio.

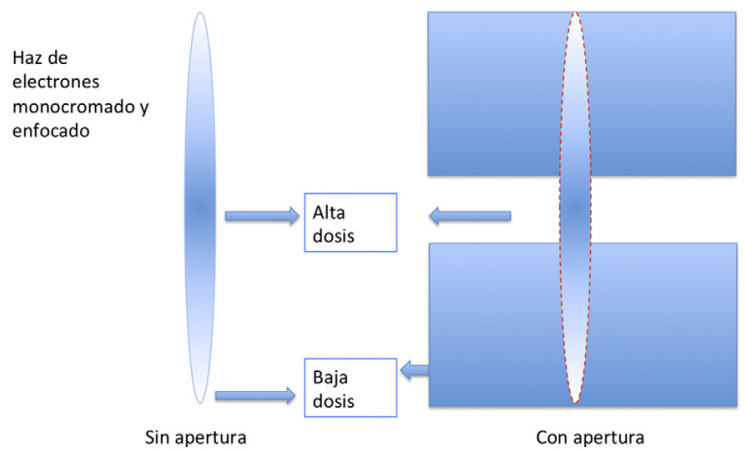

Fuente: Elaboración del autor.

trol instrumental y sus parámetros permiten alcanzar un contraste atómico que diferencie en la imagen elementos pesados de ligeros, es decir, lograr una resolución atómica en adición a una buena resolución espacial.

La figura 13 muestra imágenes experimentales de grafeno (figura 13a-c) a diferentes valores de enfoque y con una dosis temporal de $60 \mathrm{e}^{-} / \AA^{2} \mathrm{~s}$. Las

Figura 13. Imágenes de grafeno a diferentes posiciones de enfoque. a) $+15 \mathrm{~nm}$; b) $-9 \mathrm{~nm}$; c) $20 \mathrm{~nm}$; d) FFT de (a).
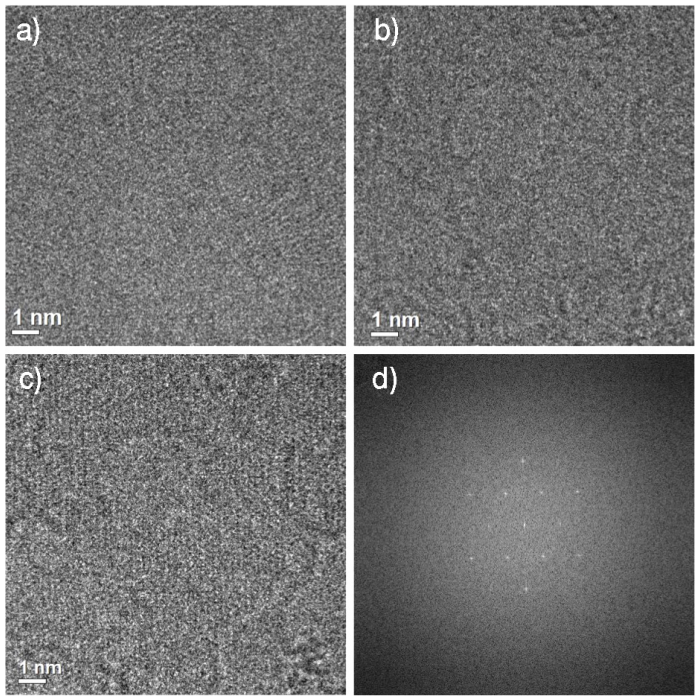

Nota: Todas las imágenes han sido obtenidas con una dosis temporal de $60 \mathrm{e}^{-} / \AA^{2} \mathrm{~s}$. Fuente: Elaboración del autor. 
Figura 14. a) Imagen de amplitud; b) imagen de fase; c) patrón de difracción de una muestra de grafeno después de reconstrucción de la onda de salida a partir de 40 imágenes experimentales en una serie focal.
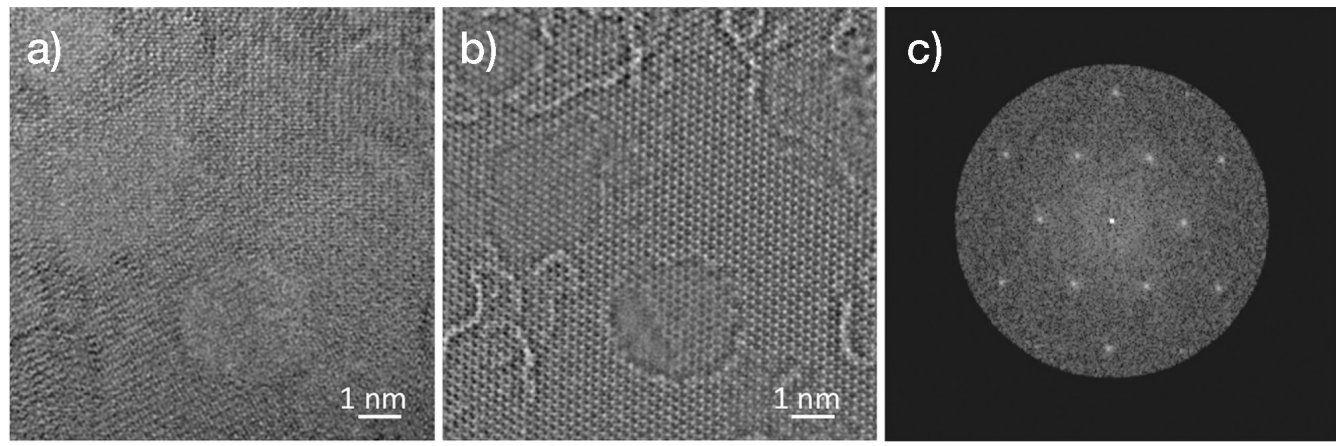

Fuente: Elaboración del autor.

imágenes tienen un contraste muy bajo para poder distinguir detalles específicos; sin embargo, contienen información relevante como lo muestra la transformada de Fourier en la figura 13d. Usando 40 imágenes en una serie focal alrededor del desenfoque de Lichte, se obtiene la función de onda reconstruida con ayuda del software MacTempass ${ }^{\circledR}$. A partir de esta onda se recuperan las imágenes de amplitud y de fase que se muestran en la figura 14a-b. El patrón de difracción correspondiente (figura 14c) es más intenso pero idéntico al mostrado anteriormente en la figura 13d. La imagen de fase tras un filtrado débil produce la imagen en la figura 15a. En estas imágenes de fase se pueden distinguir claras diferencias de contraste en los máximos de intensidad que deben relacionarse directamente con el número de átomos en cada punto. La imagen de fase representa la proyección en espesor de la muestra punto por punto o átomo por átomo. La figura $15 \mathrm{~b}$ presenta una comparación entre la simulación de la proyección de la estructura del grafeno y la imagen de fase. A partir de estas comparaciones es posible concluir acerca del número de átomos y, en consecuencia, el número de capas en espesor de la muestra, como se indica en la imagen de la figura 15a. La imagen de fase proporciona todos los elementos para comparar con un modelo de la distribución atómica del grafeno y concluir sobre el espesor de las distintas zonas (Barton et al., 2012). La imagen en la figura 15c es una amplificación de la zona central de la muestra investigada. Aquí, es posible distinguir plenamente el contraste atómico y al comparar con la estructura simulada es posible caracterizar completamente la muestra. Los números en la figura 15a indican el número de capas de espesor de la muestra para diversas regiones en la imagen. En la región de una sola capa puede inferirse una ligera inclinación de la muestra en regiones cercanas al vacío. El contraste atómico en esta imagen se relaciona directamente con la inten- 
Mundo Nano | ARTículos DE REVISIóN | www.mundonano.unam.mx

13(25), 133-156, julio-diciembre 2020 | https:// doi.org/10.22201/ceiich.24485691e.2020.25.69649

Héctor A. Calderón

Figura 15. Interpretación de imagen. a) Imagen de fase con un filtrado de Wiener débil. Los números indican la cantidad de capas atómicas de espesor en la región específica. b) Modelo atómico del grafeno. c) Región central de (a) con contraste atómico. Las diferencias en intensidad se relacionan con el número de átomos que tiene la muestra en un punto dado.
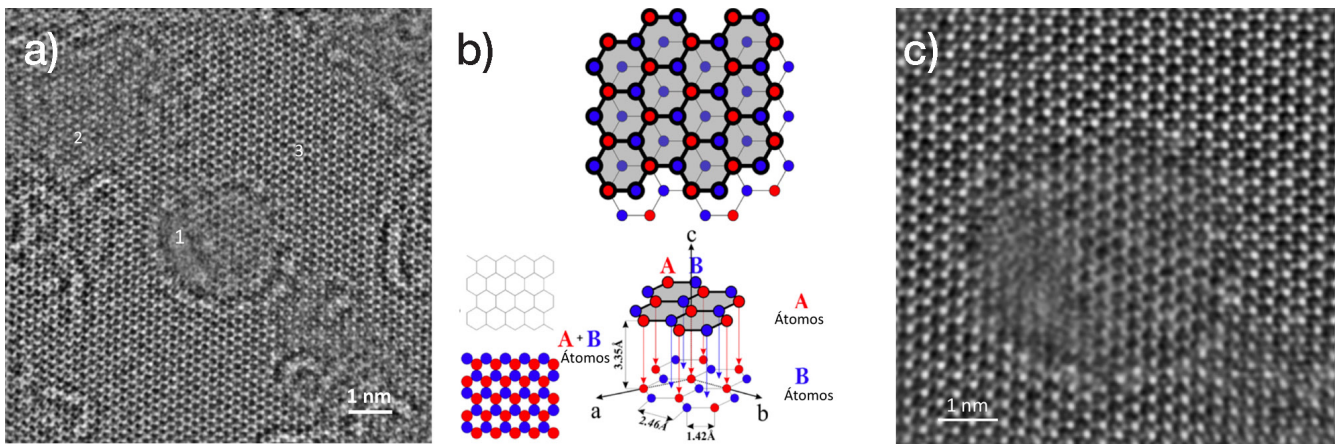

Fuente: Elaboración del autor.

sidad relativa de los máximos de intensidad y el número de átomos presentes. La zona de la monocapa tiene un contraste homogéneo de sus máximos de intensidad, la zona de tres capas muestra las diferencias de contraste correspondientes al arreglo atómico que puede inferirse de la figura 15b. La estructura del grafeno implica una sucesión de capas atómicas desplazadas que coinciden en puntos específicos cuando se proyecta en una dirección específica como en el caso de este experimento. Hay que recordar que la imagen mostrada en las figuras 15 c y 15 a se forma como resultado de una proyección de la estructura atómica a lo largo de la dirección del haz electrónico.

Los compuestos ZnS Bipy son materiales híbridos (orgánico-inorgánico) que han sido desarrollados como catalizadores para fotocatálisis (Ramírez-Rave et al., 2015. La caracterización por microscopía electrónica se realizó con éxito a pesar de ser un material extremadamente sensible al haz electrónico y usando series focales para dar como resultado imágenes de fase y amplitud. La figura 16a exhibe una imagen experimental con una dosis temporal de $30 \mathrm{e}^{-} / \AA^{2}$ s obtenida en una serie focal en el microscopio TEAM 0.5 del NCEM en el Lawrence Berkeley National Laboratory de Berkeley California. Este microscopio está equipado con un monocromador y corrector de aberración esférica. Existe un contraste débil en la imagen experimental, pero la imagen de fase correspondiente (figura 16b) tiene contraste atómico claro y se encuentra cercana al límite de resolución teórico.

Las imágenes de fase obtenidas presentan la estructura del compuesto $\mathrm{ZnS}$ y la estructura del material orgánico (bipiridina) que mimetiza al ZnS en algunas regiones. Las columnas atómicas presentan una intensidad diferente de acuerdo con el peso atómico del elemento mayoritario que las com- 
Figura 16. Compuesto híbrido ZnS Bipi. a) Imagen experimental a un desenfoque de -20 $n \mathrm{~m}$. b) Imagen de fase de zona delgada de la muestra con resolución atómica; se observan diferencias de intensidad en las columnas atómicas de acuerdo con su peso atómico. c) Simulación sobreimpuesta de la estructura del compuesto ZnS.
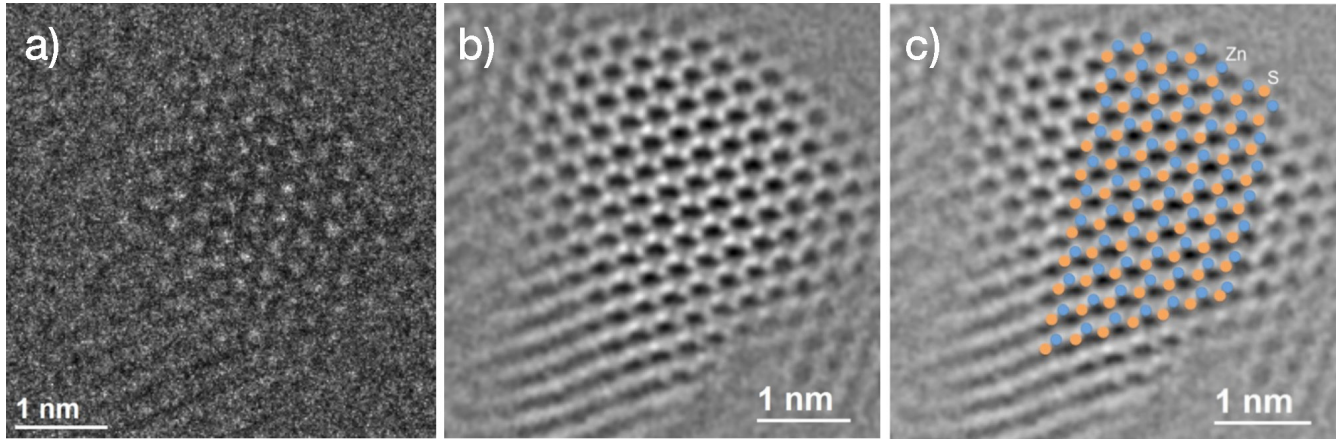

Fuente: Elaboración del autor.

pone. El compuesto orgánico adquiere la simetría del compuesto inorgánico, en la esquina derecha de la figura $16 \mathrm{~b}$ se logra retener al compuesto orgánico (la simetría se vuelve difusa) con la baja dosis utilizada. En la figura 16c, se presenta la estructura del compuesto inorgánico $\mathrm{ZnS}$ simulada y sobrepuesta en la imagen de fase. Este ejercicio identifica plenamente la muestra, y justifica el análisis realizado que concuerda con la distribución atómica encontrada experimentalmente.

La figura 17a muestra la zona anterior en un campo de vista más amplio. La muestra tiene una sección muy delgada en donde las dos fases, orgánica e inorgánica pueden observarse en contacto y corresponde a la sección mostrada en la figura 16. Adicionalmente, la figura 17a muestra una sección que pierde el ordenamiento estricto del $\mathrm{ZnS}$ y que muy probablemente consiste de una región puramente orgánica y se identifica con RO. Esta región puede conservarse en 40 imágenes experimentales y observarse en la imagen de fase como resultado de la baja dosis de electrones en uso, y permite mantener la estructura genuina sin afectar zonas tan sensibles de la muestra. Cualquier aumento de la dosis provoca una reacción en la región orgánica que termina con la expulsión de materia en esa región particular. La figura $17 \mathrm{~b}$ muestra la misma zona después de $10 \mathrm{~s}$ con una dosis más alta de 380 $\mathrm{e}^{-} / \AA^{2} \mathrm{~s}$, como resultado de la mediana interacción con el haz, la región se ha comprimido considerablemente pero el contraste atómico y la baja dosis temporal usada para la serie focal de reconstrucción permite mantener la estructura cristalina sin mayor daño, aunque con dimensiones reducidas. Un nuevo ejercicio de aumento de dosis por un tiempo de 5 s provoca un adelgazamiento subsecuente y el resultado se muestra en la imagen de la figura 17c. La pérdida de átomos como resultado de la interacción con el haz es 
Mundo Nano | ARTículos DE REVISıón | www.mundonano.unam.mx

13(25), 133-156, julio-diciembre 2020 | https:// doi.org/10.22201/ceiich.24485691e.2020.25.69649

Héctor A. Calderón

Figura 17. Efecto de la dosis e interacción con la muestra de ZnS-bipiridina, en todos los casos se utiliza una dosis temporal de $30 \mathrm{e}^{-} / \AA^{2} \mathrm{~s}$ para adquirir 40 imágenes y recuperar imágenes de fase. a) Muestra sin irradiación adicional; b) muestra irradiada por $10 \mathrm{~s}$; c) muestra irradiada $20 \mathrm{~s}$ en total. La irradiación se hace con una dosis temporal de $380 \mathrm{e}^{-} / \AA^{2} \mathrm{~s}$.
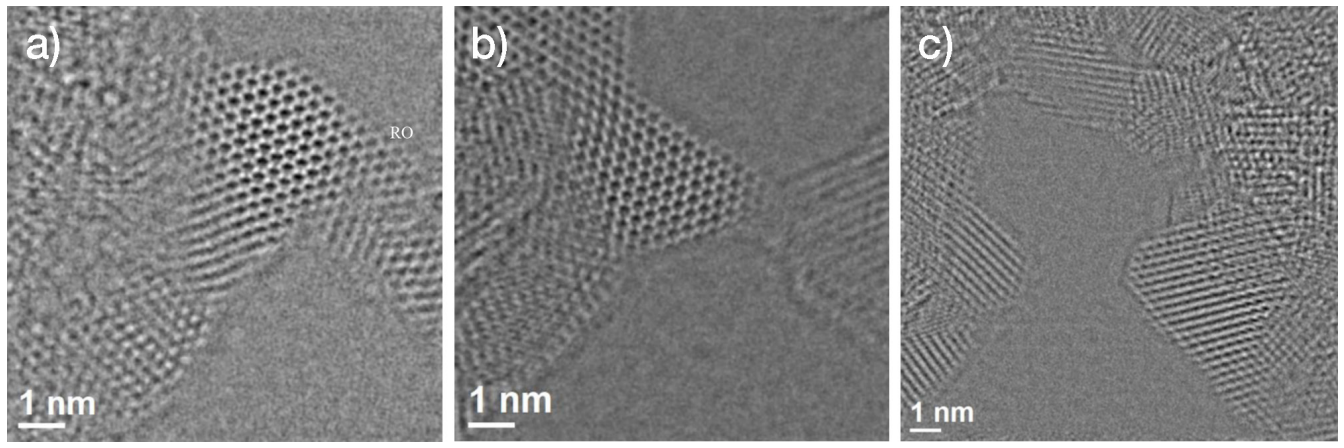

Fuente: Elaboración del autor.

clara y ha afectado considerablemente la muestra. Resulta aparente que el control de la cantidad de electrones que impactan la muestra es de suma importancia para mantener la estructura genuina del nanomaterial a caracterizar, especialmente en este caso con una muestra sensible.

El desarrollo de baterías recargables de bajo costo con materiales abundantes y simples es de importancia considerable en aplicaciones energéticas como transportación eléctrica y de almacenamiento de energía en redes. Las baterías de $\mathrm{Mg}$ representan una tecnología segura y de alta energía pero tienen el inconveniente de una gran escasez de materiales adecuados para el cátodo de la batería, esto se debe a la difusión lenta en estado sólido de los iones polarizantes y divalentes de $\mathrm{Mg}$ (Yoo et al., 2015). Un método para optimizar el transporte de Mg consiste en realizar una expansión de intercapas al nivel atómico, el objetivo es transformar los materiales intercalando residentes originales inactivos en materiales eficientes para almacenar $\mathrm{Mg}$ sin introducir efectos adversos. En una publicación reciente, experimentalmente se intercaló óxido de polietileno (PEO) en una material inorgánico $\mathrm{MoS}_{2}$ para aumentar la distancia intercapas del material de $0.62 \mathrm{~nm}$ a 1.45 $\mathrm{nm}$. La figura 18 muestra una imagen experimental en bajas dosis (15 $\mathrm{e}^{-} /$ $\AA^{2}$ s) del compósito PEO-MoS 2 , y una imagen de fase después de reconstrucción, las capas de material orgánico e inorgánico son aparentes y su espesor puede medirse con relativa sencillez. La imagen conserva detalles del PEO y del compuesto inorgánico $\mathrm{MoS}_{2}$ que pueden correlacionarse a las propiedades a través del espaciamiento entre capas, esto y su relación con el proceso de síntesis se describe en la publicación referida (Yoo et al., 2015). Es importante constatar que la muestra no fue afectada por el haz, a pesar de la gran sensitividad de PEO al flujo electrónico. 
Figura 18. Material compuesto MoS2-PEO para baterías. a) Imagen experimental con un desenfoque de $0 \mathrm{~nm}$; b) imagen de fase con resolución atómica.
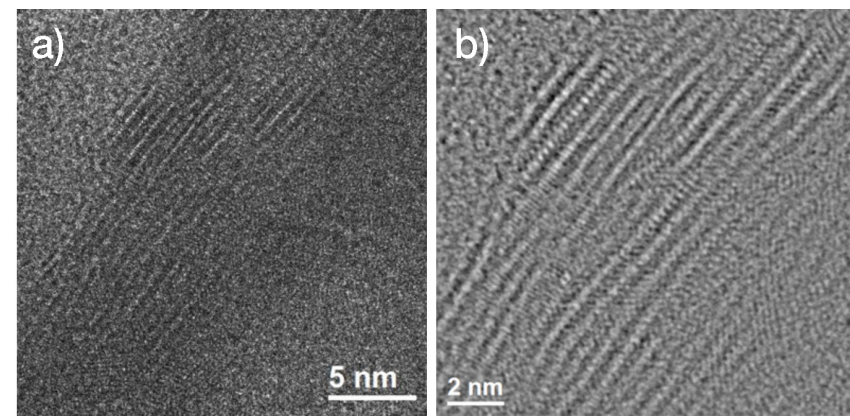

Fuente: Elaboración del autor.

\section{Imágenes de STEM}

Las imágenes de STEM de alta resolución se producen al enfocar el haz en un punto y registrar la intensidad dispersada en un detector y tienen características de contraste $Z$. Especies atómicas con altos números atómicos tienen una fuerte dispersión incoherente y el detector anular registra altas intensidades, esto es, átomos pesados producen intensidades más altas que elementos más ligeros. La dependencia entre la intensidad incoherente dispersada y el número atómico es relativamente regular con $\mathrm{Z}$ y puede representarse con una curva. En la aplicación de técnicas de STEM, también es importante considerar la dosis de electrones en uso pues, un haz concentrado o enfocado como el que se emplea en el método, puede alterar la morfología de los nanocristales (nanopartículas, nanoalambres o capas nanométricas) en la muestra al promover variaciones en el arreglo atómico de estos. Normalmente, el barrido se realiza con una dosis baja menor a 100 e/ $\AA^{2}$ s y se aumenta el contraste para mejor visualización traslapando numéricamente las imágenes. Es decir, se requiere usar un método de alineación muy preciso y registrar la intensidad acumulada en el traslape por cada pixel en la imagen. Se emplean series de 20-40 imágenes sucesivas adquiridas con barridos rápidos y en idénticas condiciones instrumentales, solo tienen un contraste bajo debido a las bajas dosis en uso. Un ejemplo de este método se presenta en la figura 19, la cual muestra pozos cuánticos de CdSe en ZnSe en STEM con resolución atómica. La geometría de los pozos cuánticos se presenta en la figura 19a. Durante la síntesis del conjunto se emplea, por supuesto, material de soporte y el pozo cuántico de CdSe con unas cuantas monocapas de espesor entre capas de ZnSe. Las imágenes de STEM se presentan en las figuras $19 b-d$, en ellas se observa un contraste diferente para el pozo cuántico ultradelgado de CdSe/ZnSe en campo claro (figura 19b), campo oscuro de alto ángulo (HAAD, figura 19c) y la imagen con colores artificiales (figura 19d) para hacer más clara la geometría del pozo cuántico. En 
Mundo Nano | ARTículos DE REVISıón | www.mundonano.unam.mx

13(25), 133-156, julio-diciembre 2020 | https:// doi.org/10.22201/ceiich.24485691e.2020.25.69649

Héctor A. Calderón

Figura 19. Pozos cuánticos de CdSe/ZnSe. a) Geometría del arreglo de capas depositadas para formar pozos cuánticos. b) Imagen de STEM en campo claro. c) Imagen de STEM en campo oscuro de ángulo alto (HAAD) en el detector anular. d) Imagen con colores artificiales y mayor contraste.
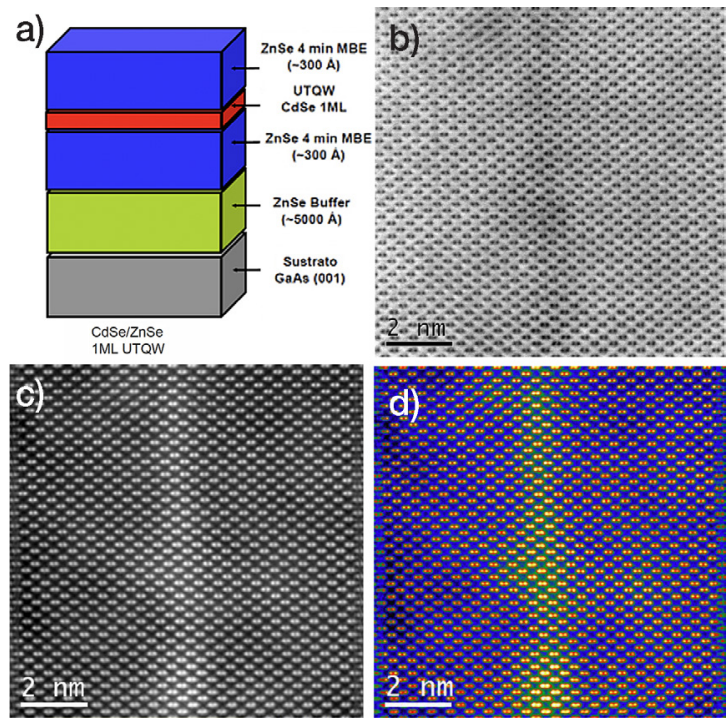

Fuente: Elaboración del autor.

todos los casos, la dosis electrónica usada es menor a 100 e/ $\AA^{2}$ s. La emisión excitónica de estos pozos cuánticos pseudomórficos con un espesor de algunas monocapas estructurales (ML) puede ajustarse en el intervalo espectral comprendido entre el verde-amarillo y azul. Así, resultan materiales muy atractivos para emplearse en la fabricación de LEDS y láseres. Estructuralmente CdSe y ZnSe son similares, ambos compuestos son cúbicos y tienen parámetros reticulares muy cercanos $\left(a_{\mathrm{ZnSe}}=0.566 \mathrm{~nm} ; a_{\mathrm{CdSe}}=0.608 \mathrm{~nm}\right)$ por lo que existe una coherencia perfecta en arreglos de hasta $3 \mathrm{ML}$. La figura 20 exhibe resultados de simulación de estas estructuras, indispensables para una correcta interpretación del trabajo experimental. La figura 20a muestra la simulación del arreglo estructural de estos pozos cuánticos, mientras que en las figuras 20b-c se muestran las proyecciones estructurales de ambos compuestos en la dirección $B=$ [011]. Los modos del STEM se definen anteriormente en la figura 4, el campo claro se toma con la señal transmitida directamente mientras que el HAAD se obtiene usando un detector anular. En las imágenes de la figura 19 se observa contraste $Z$ con una resolución de aproximadamente $0.1 \mathrm{~nm}$. Las parejas de átomos en la proyección corresponden con la simulación presentada en la figura 20b para el eje de zona B = [011]. Las columnas de átomos ricas en Cd, Se y Zn pueden distinguirse claramente en las imágenes experimentales e interpretarse adecuadamente con ayuda de la simulación. 
Figura 20. Simulación estructural de pozos cuánticos CdSe/ZnSe. a) Arreglo de estructuras de pozo cuántico. b) Proyección estructural del compuesto CdSe de acuerdo con su estructura cúbica c) Proyección de la estructura cristalina del compuesto ZnSe. En ambos casos la proyección se realiza usando la dirección $B=$ [011] como eje de proyección (dirección cristalina paralela al haz de electrones en el experimento). La representación atómica es como sigue: Se $\bigcirc, \mathrm{cd} \bigcirc, \mathrm{zn} \bigcirc$.

(a)

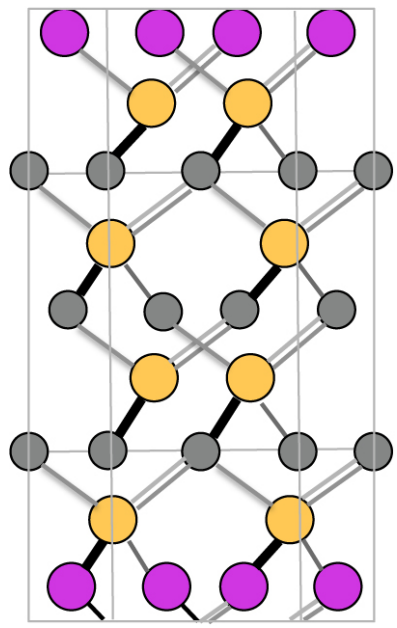

(b)

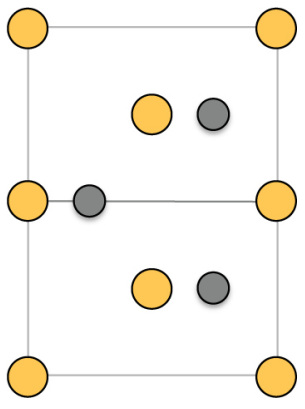

(c)

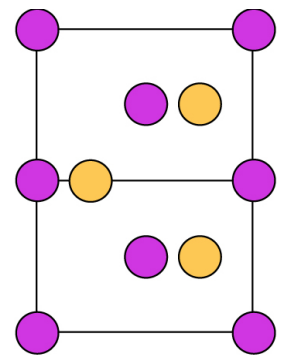

Fuente: Elaboración del autor.

\section{Comentarios finales}

La microscopía electrónica de transmisión es una herramienta útil en la caracterización de materiales nanoestructurados. Esta técnica puede proveer información de importancia acerca de la distribución de átomos en un material con alta resolución espacial y con sensitividad a la naturaleza de los componentes, es decir, una resolución atómica. Este trabajo se centra en la descripción y aplicación de esta herramienta mostrando diversos ejemplos en los que aplica un método de trabajo con bajas dosis del haz electrónico. Las ventajas de esta aplicación son conservar la integridad de los materiales y poder utilizar el resultado directamente para correlacionarse con las propiedades de interés de los nanobloques.

\section{Referencias}

Barton, B. Jiang, C. Y. Song, Petra Specht, H. A. Calderon y C. Kisielowski. (2012). Microscopy and Microanalysis, 18 (05): 982-994. https://doi.org/10.1017/ S1431927612001213

Gerchberg, R. W., W. O. Saxton. (1972). Optik, 35: 237. 
Haider, M., H. Rose, S. Uhlemann, E. Schwan, B. Kabius, K. Urban. (1998). Ultramicroscopy, 75: 53-60. https://doi.org/10.1016/S0304-3991(98)00048-5

Hsieh, W. K., Hsieh, F.-R. Chen, J.-J. Kai, A.I Kirkland. (2004). Ultramicroscopy, 98: 99. https://doi.org/10.1016/j.ultramic.2003.08.004

Kilaas, R. Software package. https://www.totalresolution.com

Kisielowski, C. H. Frei, I. D. Sharp, J. A. Haber, S. Helveg (2016). Adv. Struct. Chem. Imaging, 2: 13. https://doi.org/10.1186/s40679-016-0027-9

Kisielowski, C., C. J. D. Hetherington, Y. C. Wang, R. Kilaas, M. A. O’Keefe, A. Thust. (2001). Ultramicroscopy, 89: 243-263. https://doi.org/10.1016/S0304-3991(01)00090-0

Lichte, H., M.Lehman. (2008). Rep.Prog.Phys. 71:016102. https://doi.org/10.1088/00344885/71/1/016102

Lichte, H. (1991). Ultramicroscopy, 38(13). https://doi.org/10.1016/0304-3991(91) 90105-F

Mobus, G., F. Phillipp, T. Gemming, R. Schweinfest, M. Ruhle. (1997). J. Electron Microscopy, 46: 381-395. https://doi.org/10.1093/oxfordjournals.jmicro.a023534

Nellist, P. D. y S. J. Pennycook. (1998). Phys. Rev. Lett., 81: 4156. https://doi.org/10.1103/ PhysRevLett.81.4156

Pennycook, S. J., Varela, M., Hetherington, C. J. D. y Kirkland, A. I. (2006). Materials advances through aberration- corrected electron microscopy. MRS Bulletin, 31: 36-43. http://dx.doi.org/10.1557/mrs2006.4

Press Release. The Nobel Prize in Physics 1986. The Royal Swedish Academy of Sciences. Octubre 15, 1986.

Ramírez-Rave, S., A. Hernández-Gordillo, H. A. Calderón, A. Galano, C. García-Mendoza y R. Gómez. (2015). New Journal of Chemistry, 39: 2188-2194. https:// doi.org/10.1039/C4NJ01891E

Tiemeijer, P. C., M. Bischoff, B. Freitag, C. Kisielowski. (2012). Ultramicroscopy, 118: 35-43. https://doi.org/10.1016/j.ultramic.2012.03.019

Yoo, H.-D. , Y. Liang, Y. Li, H. A. Calderón, F. Robles, S. Jing, L. C. Grabow y Y. Yao. (2015). Nano Letters, 15: 2194-2202. https://doi.org/10.1021/acs.nanolett.5b00388 